\title{
Association Between Onychomycosis and Foot Ulcers in Patients with Diabetes Mellitus
}

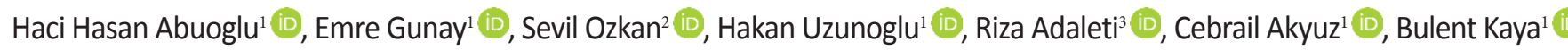 \\ ${ }^{1}$ Haydarpasa Numune Training and Research Hospital, Department of General Surgery, Istanbul, Turkey. \\ ${ }^{2}$ Haydarpasa Numune Training and Research Hospital, Department of Internal Medicine, Istanbul, Turkey. \\ ${ }^{3}$ Haydarpasa Numune Training and Research Hospital, Department of Microbiology, Istanbul,Turkey.
}

Correspondence Author: Haci Hasan Abuoglu

E-mail: abuoglu@gmail.com

Received: $20.06 .2018 \quad$ Accepted: 30.07 .2018

\begin{abstract}
Objective: Diabetes mellitus (DM) is associated with many serious health complications such as diabetic foot ulcer (DFU). Onychomycosis increases the risk for foot disorders and limb amputation in DM patients, and if untreated, can result in tissue degradation and DFU. Therefore, this study aimed to determine the association between the incidences of onychomycosis and DFU.

Methods: This study included 40 DM patients with DFU (study group) and 40 DM patients without FU (control group). Samples were obtained from the most affected part of the nail. The deep-nail plaque of the right toe was preferred in patients with normal toenail appearance. In addition, mycological examinations were conducted. Values of $p<0.01$ were considered as significant.

Results: No significant difference was observed between the two groups with respect to age, sex, and hemoglobin A1c levels $(p<0.01)$. However, the incidence of onychomycosis and use of insulin were significantly higher in the study group than in the control group ( $p<0.01$ and $p<0.001$, respectively).

Conclusion: Onychomycosis might be associated with development of FU in patients with DM. By treating onychomycosis early, foot amputation can be prevented.
\end{abstract}

Keywords: Diabetes Mellitus, Diabetic Foot, Risk Factors, Onychomycosis

\section{INTRODUCTION}

Diabetes mellitus (DM) is a chronic metabolic disease that affects all age and socioeconomic groups.The number of people with diabetes was estimated to be 285 million in 2010 and is projected to increase to 439 million by 2030 (1). In patients with DM, local and systemic infections occur frequently and with higher severity as compared to the normal population (2). Two such infections onychomycosis and tinea pedis comprise the majority of these infections $(3,4)$. In this study, we focused on onychomycosis, which is the most common nail disease with an incidence of $2-26 \%$ worldwide (5) and $15.8-26.0 \%$ in Turkey $(6,7)$. Notably, this fungal infection is responsible for $30 \%$ of all superficial fungal infections(8).

Foot ulceration is one of the most hazardous complications of DM, as it is the most common cause of non-traumatic foot amputation (vascular disease, diabetes, or combination of both) worldwide. Patients with diabetes are 15-20 times more prone to amputation than those without DM (9). The prevalence of diabetic foot ulcers (DFUs) ranges from $4 \%$ to $10 \%$ in hospitalized patients, and the lifelong risk of developing FUs may reach $25 \%$ in patients with diabetes(10). Once an FU develops, the risk of foot amputation increases due to rapid wound progression, and approximately $5 \%$ of diabetics develop FUs each year and $1 \%$ have require amputation (11).

Onychomycosis increases the risk for foot disorders and limb amputation in patients with diabetes in addition to affecting the cosmetic appearance of the foot (12). Therefore, optimum treatment is mandatory for diabetic patients with onychomycosis (13).

Many studies have thus far assessed the prevalence of onychomycosis in patients with diabetes. Gupta et al. reported a prevalence of $26 \%$ for onychomycosis in diabetic patients (12), whereas Mayser et al. reported a prevalence of $59 \%$ for the same (14). Impaired sensation in diabetic patients may indicate the presence of traumatic and onychomycotic lesions, which may become a potential portal of entry for bacterial infections that can aggravate DF (15). Therefore, in this study, our aim was to determine the relationship between the incidence of onychomycosis and that of DFU in patients with diabetes.

\section{METHODS}

\subsection{Patients}

The study was conducted at the general surgery, orthopedics, internal medicine, and microbiology clinics of the hospital 
between February 2013 and July 2013. The study group composed 40 patients with DM and $\mathrm{FU}$ and the control group comprised 40 patients with DM but without FU.

Inclusion criteria for the study were as follows: no receipt of oral and/or topical antifungal therapy in the last two months and no current immunosuppression. All patients included were aged $>18$ years and had similar treatment statuses. Patients with gestational diabetes and excessive peripheral vascular disorder were excluded from the study.

All data were obtained from patients by face-to-face interview. Approval was obtained from each patient by using a form that included information on age, sex, hemoglobin $\mathrm{A} 1 \mathrm{c}(\mathrm{HbA} 1 \mathrm{c})$ levels, and treatment status (intake of oral antidiabetic drugs versus subcutaneous insulin).

\subsection{Laboratory data}

The HbA1c levels (\%) were detected by high-performance liquid chromatography (HPLC) (Agilent 1200 Series, UV, Shimadzu Class-VP, Kyoto, Japan). The normal range was 4.4$6 \%$ of the reference range. The $\mathrm{HbA} 1 \mathrm{c}$ measurements were performed in a specific order: $0.1 \mathrm{mM}$ ethylene diamine tetra acetic acid and $25 \mathrm{mM}$ Tris- $\mathrm{HCl}$ were mixed with 500 $\mathrm{mL}$ distilled water to prepare the hemolysate $(\mathrm{pH}: 8.7)$. Thereafter, $1 \mathrm{~mL}$ hemolysate was added to $5 \mu \mathrm{L}$ complete blood and incubated for $20 \mathrm{~min}\left(37.2^{\circ} \mathrm{C}\right)$ to allow the erythrocytes to disintegrate. The mixture was then loaded into the HPLC instrument mentioned above.

\subsection{Sample processing}

Samples were obtained from the most-affected part of the nail. After cleaning the area with $70 \%$ alcohol, the affected part was scraped using a scalpel. The deep-nail plaque of the right toe was preferred for patients with normal toe appearance. However, the most-affected site was preferred for diabetic patients with onychomycosis. Sterile plastic containers were used for preservation of samples during transport.

Two drops of $20 \% \mathrm{KOH}$ were added and a coverslip was applied. Thereafter, the sample was incubated for $3 \mathrm{~h}$ until the specimen softened. The results of direct microscopic examination were recorded as positive or negative for fungus. Sabouraud dextrose agar with chloramphenicol (Merck, Germany) was used for culture plating of the sample in the clinical microbiology laboratory. The agar plates were incubated for 4 weeks at room temperature $\left(26^{\circ} \mathrm{C}\right)$, after which the observations were recorded.

\subsection{Ethical consideration}

Approval from the local ethics committee was obtained for this study (10.12.2012-2012/90) and written informed consent was obtained in accordance with the Declaration of Helsinki from all patients. Privacy rights of the patients have been observed.

\subsection{Statistical analysis}

The Number Cruncher Statistical System (NCSS) 2007\&Power Analysis and Sample Size (PASS) 2008 statistical software (Utah, USA) program was used for statistical analysis. Statistical measures such as mean, standard deviation (SD), frequency, ratio, minimum and maximum were used to evaluate the data. Student's $t$-test was used to compare the normally distributed groups, and Fisher's exact test or Yates' Continuity Correction test (Yates corrected QHI-square) was used for analysis of qualitative data. Values of $p<0.01$ were considered significant.

\section{RESULTS}

The sex distribution was similar in both groups, and the ages in both groups ranged from 40 to 81 years (mean \pm SD, $60.19 \pm 9.40$ years). There was no significant difference between the two groups with regard to age and sex ( $p>0.05)$.

Importantly, the prevalence of onychomycosis was $40 \%$ in the study group, i.e., DM patients with DFU, and $12.5 \%$ for the control group, i.e., DM patients without DFU (Table 1). The $\mathrm{HbA} 1 \mathrm{c}$ levels ranged between $5.5 \%$ and $14.3 \%$, with a mean of $7.82 \% \pm 1.64 \%$. The mean $\mathrm{HbA1c}$ value in the study group was $7.66 \% \pm 1.42 \%$, whereas that in the control group was $7.98 \% \pm 1.84 \%$. Furthermore, $40 \%$ of all patients $(n=32)$ were receiving oral anti-diabetic drugs, and the remaining $60 \%(n=48)$ were receiving subcutaneous insulin. Direct microscopic examination of the samples yielded a negative result in $86.2 \%(n=69)$ of the patients and a positive result in the remaining $13.8 \%(n=11)$ of patients. In addition, culture results were negative in $74 \%$ of the patients and $(n=59)$ and positive in $26 \%$ patients $(n=21)$. The HbA1c levels and microscopic examination results did not show any significant difference between groups ( $p>0.05)$.

Table 1. Characteristics of patients in the study group (diabetic patients with diabetic foot ulcers) and control group (diabetic patients without diabetic foot ulcers)

\begin{tabular}{|c|c|c|c|c|c|}
\hline & $\begin{array}{l}\text { Total } \\
(n=80)\end{array}$ & $\begin{array}{l}\text { Study } \\
\text { group } \\
(n=40)\end{array}$ & $\begin{array}{l}\text { Control } \\
\text { group } \\
(n=40)\end{array}$ & \multirow[t]{2}{*}{$p$} \\
\hline & & Mean $\pm S D$ & Mean \pm SD & Mean $\pm S D$ & \\
\hline \multicolumn{2}{|l|}{ Age (years) } & $60.19 \pm 9.40$ & $60.10 \pm 9.88$ & $60.28 \pm 9.03$ & $0.934^{\mathrm{a}}$ \\
\hline \multicolumn{2}{|l|}{ HbA1c } & $7.82 \pm 1.64$ & $7.66 \pm 1.42$ & $7.98 \pm 1.84$ & $0.387^{a}$ \\
\hline & & n (\%) & n (\%) & n (\%) & \\
\hline \multirow{2}{*}{ Sex } & Female & $40(50.0)$ & $16(40.0)$ & $24(60.0)$ & \multirow{2}{*}{$0.118^{b}$} \\
\hline & Male & $40(50.0)$ & $24(60.0)$ & $16(40.0)$ & \\
\hline \multirow{2}{*}{ Drug use } & OAD & $32(40.0)$ & $8(20.0)$ & $24(60.0)$ & \multirow{2}{*}{$0.001^{\mathrm{b}, * *}$} \\
\hline & Insulin & $48(60.0)$ & $32(80.0)$ & $16(40.0)$ & \\
\hline \multirow{2}{*}{$\begin{array}{l}\text { Microscopy } \\
\text { results }\end{array}$} & Negative & $69(86.2)$ & $33(82.5)$ & $36(90.0)$ & \multirow{2}{*}{$0.516^{b}$} \\
\hline & Positive & $11(13.8)$ & $7(17.5)$ & $4(10.0)$ & \\
\hline \multirow{2}{*}{ Culture } & Negative & $59(74)$ & $24(60.0)$ & 35 (87.5) & \multirow{2}{*}{$0.003^{\mathrm{b}, * *}$} \\
\hline & \begin{tabular}{|l|} 
Positive \\
\end{tabular} & $21(26)$ & $16(40.0)$ & $5(12.5)$ & \\
\hline
\end{tabular}

${ }^{a}$ Student's t-test, ${ }^{b}$ Yates' Continuity Correction Test or Fisher's Exact Test ${ }^{* *} p<0.01, O A D$, oral anti-diabetic drugs; HbA1c, hemoglobin $A 1 c ; S D$, standard deviation

The diabetes medication status was found to be significantly different between the groups $(p<0.001)$ : Insulin usage was 
approximately 6 times higher in the study group than in the control group (odds ratio: 6.0;95\% confidence interval [CI]: 2.207-16.313). In addition, the culture results were significantly different between groups $(p=0.003 ; p<0.01$; odds ratio for culture positivity: $4.667 ; 95 \% \mathrm{Cl}: 1.685-12.927$; Table 1).

\section{DISCUSSION}

DM is associated with various disabling health complications, especially DFU $(16,17)$. DF is the infection, ulceration, and deep tissue destruction related with neurological peripheral vascular and/or metabolic complications of DM (18). Nearly one-third of all patients with DM develop onychomycosis(12), which is responsible for $50 \%$ of all nail problems (19) and $30 \%$ of all superficial fungal infections (20). As such, it is an important factor of morbidity.

In the literature, standard microscopic examination of tissue of DFU has shown varying rates of positive results, ranging between $10 \%$ and $75 \%$ (21-23). In our study, the rate of positive results for microscopic examination was $13.8 \%$, but that by cultural studies was $26 \%$. The major cause of falsenegative results of microscopic examination is use of the uninfected part of the nail that does not contain any fungal hyphae $(21,24)$. In addition to previous topical or systemic treatment, the quality and amount of nail sample obtained are important $(21,25)$. Therefore, culture of the sample is recommended to confirm the diagnosis in suspected cases. In our study, all samples were subjected to both standard microscopic examination and culture in order to reduce the false-negative results.

Several controlled (26-30) and non-controlled studies (12,31) have evaluated the relationship between onychomycosis and DM. The frequency of onychomycosis worldwide varies widely, i.e., $6 \%-85 \%$. Some studies have reported that DM promotes onychomycosis (31), while others have reported that the frequency of onychomycosis does not vary between patients with diabetes (14.4\%) and those without diabetes (14\%) (29). In the current study, we found that the frequency of onychomycosis was $26 \%$ among the 80 patients with DM. In particular, $40 \%$ of patients in the study group had onychomycosis. This high prevalence of onychomycosis could be because macro - and microangiopathy in patients with diabetes with hypoxia and impaired immunity may facilitate the development of onychomycosis $(27,32)$.

Foot infections occur frequently in individuals with DM and dramatically increase the risk of hospitalization and amputation (33). Intravenous insulin infusions are the preferred method for achieving and maintaining glycemic control in critically ill patients and for the majority of non-critically ill patients. For some non-critical patients, scheduled subcutaneous administration of insulin with basal, nutritional, and correction components is preferred for achieving and maintaining glucose control. Additionally, non-insulin anti-hyperglycemic agents are avoided for most hospitalized patients requiring therapy for hyperglycemia
(34). In this study, the majority of patients with DFU were hospitalized because they presented with infected FUs. Therefore, insulin usage in these patients was significantly higher $(p<0.001)$ than that in the control group.

In this study, we found a significant relationship between onychomycosis and FU. It is known that onychomycosis promotes progression of DFU (35). Sharp, brittle nails can gouge the skin, creating a portal for entry of bacteria. Onychomycosis is often associated with tinea pedis, which can create fissures in the skin, paving the way for bacterial infections. The incidence of secondary infection in diabetic patients with onychomycosis and those without onychomycosis was found to be $15 \%$ and $6 \%$, respectively (36). Both fungal and bacterial secondary infections, including paronychia and cellulitis, may be caused by injury to adjacent skin from the mycotic nail. Patients are usually unaware of these injuries or infections $(12,20)$. Blisters may arise due to the pressure applied by thickened nails and hyponychium. Peripheral neuropathy may contribute to deterioration of simple erosions and blisters to cellulitis or osteomyelitis of the underlying bone $(12,20)$. Because the risk of amputation increases with onychomycosis, it is imperative for clinicians to examine the feet of diabetic patients and when the presence of infection is suspected, the clinician should obtain a sample for diagnosis.

Despite our important findings, our study has a few limitations that need to be addressed. First, the size of the study population was small. Second, we excluded patients with excessive peripheral vascular disorder, but included some patients with mild peripheral vascular disease; therefore, the influence of slight obstructions (asymptomatic, incomplete blood vessel obstruction) in the development of DFU was not excluded.

\section{CONCLUSION}

Onychomycosis might cause DFU in DM patients when left untreated and once developed, may require limb amputation. It is usually asymptomatic in otherwise healthy persons but may be responsible for progression to $\mathrm{FU}$ in patients with DM. Therefore, patients with diabetes should be routinely checked for onychomycosis.

\section{REFERENCES}

[1] Shaw JE, Sicree RA, Zimmet PZ. Global estimates of the prevalence of diabetes for 2010 and 2030. Diab Res Clin Pract 2010;87(1):4-14.

[2] Iscimen A, Arzuhal N. Cutaneus findings of diabetes mellitus. Dermatose. 2004;3:18-25.

[3] Yosipovitch G, Hodak E, Vardi P, Shraga I, Karp M, Sprecher $E$, David M. The prevalence of cutaneous manifestations in IDDM patients and their association with diabetes risk factors and microvascular complications. Diabetes Care. 1998;21(6):506-509.

[4] Ascı Z, Seyrek A, Kizirgil A, Yılmaz M. Tinea unguium investigated in patients with diabetes. Turk J Infect 1996;10:365-367. 
[5] Jaffe R. Onychomycozis: recognition, diagnosis, and management. Arch Fam Med 1998;7:587-592.

[6] Kiraz M, Yegenoglu Y, Erturan Z. The epidemiology of onychomycoses in Istanbul, Turkey. Mycoses. 1999;42(4):323329.

[7] Ilkit M. Onychomycosis in Adana, Turkey: a 5-year study. Int J Dermatol 2005;44:851-854.

[8] Segal R, Kimchi A, Kritzman A, Inbar R, Segal Z. The frequency of Candida parapsilosis in onychomycosis. An epidemiological survey in Israel. Mycoses. 2000;43(9-10):349-353.

[9] Tabatabaei-Malazy O, Mohajeri-Tehrani MR, Pajouhi M, Shojaei Fard A, Amini MR, Larijani B. Iranian diabetic foot research network. Adv Skin Wound Care. 2010;23:450-454.

[10] Marston W. A.; Dermagraft Diabetic Foot Ulcer Study Group. Risk factors associated with healing chronic diabetic foot ulcers: the importance of hyperglycemia. Ostomy. Wound. Manage. 2006;52(3):26-29.

[11] Reiber GE, Vileikyte L, Boyko E. J, del Aguila M, Smith DG, Lavery LA, Boulton AJ. Causal pathways for incident lower extremity ulcers in patients with diabetes from two settings. Diabetes Care. 1999;22(1): 157-162.

[12] Gupta AK, Konnikov N, MacDonald P, Rich P, Rodger NW, Edmonds MW, McManus R, Summerbell RC. Prevalence and epidemiology of toenail onychomycosis in diabetic subjects: a multicentre survey. Br J Dermatol 1998;139(4):665671.

[13] Gupta AK, Humke S. The prevalence and management of onychomycosis in diabetic patients. Eur J Dermatol 2000;10(5):379-384.

[14] Mayser P, Hensel J, Thoma W, Podobinska M, Geiger M, Ulbricht $H$, Haak T. Prevalence of fungal foot infections in patients with diabetes mellitus type 1-underestimation of moccasin-type tinea. Exp Clin Endocrinol Diabetes. 2004;112(5):264-268.

[15] Rich P. Special patient populations: onychomycosis in the diabetic patient. J Am Acad Dermatol. 1996;35(3):10-12.

[16] Boulton A, Vinik A, Arezzo J, Bril V, Feldman EL, Freeman R, Malik RA, Maser RE, Sosenko JM, Ziegler D; American Diabetes Association. Diabetic Neuropathies: a statement by the American Diabetes Association. Diabetes Care. 2005;28(4):956-962.

[17] Chand G, Mishra AK, Kumar S, A. Agarwal A. Diabetic foot. Clin. Queries: Nephrol 2012;1(2):144-150.

[18] Williams R, Van Gaal L, Lucioni C. Assessing the impact of complications on the costs of type II diabetes. Diabetologia. 2002;45(7):13-17.

[19] Faergemann J, Baran R: Epidemiology, clinical presentation and diagnosis of onychomycosis. Br J Dermatol. 2003;49 Suppl 65:1-4.
[20] Rich P, Hare A. Onychomycosis in a special patient population: focus on the diabetic. Int J Dermatol 1999;38 Suppl:17-19.

[21] Daniel CR, Elewski BE. The diagnosis of nail fungus infection revisited. Arch Dermatol 2000;136:1162-1164.

[22] Grover C, Reddy BSN, Chaturvedi KU. Onychomycosis and the diagnostic significance of nail biopsy. J Dermatol 2003;30(2):116-122.

[23] Machler BC, Kirsner R RS, Elgart GW. Routine histologic examination for the diagnosis of onychomycosis: an evaluation of sensitivity and specificity. Cutis. 1998;61:217-219.

[24] Fletcher CL, Hay JR, Smeeton NC. Onychomycosis: the development of a clinical diagnostic aid for toenail disease: Part I. Establishing discriminating historical and clinical features. Br J Dermatol 2004;150:701-705.

[25] Elewski BE. Diagnostic techniques for confirming onychomycosis. J Am Acad Dermatol 1996;35(3):6-9.

[26] Somolinos AL, Sànchez JL. Prevalence of dermatophytosis in patients with diabetes. J Am Acad Dermatol 1992;26(3):408410.

[27] Dogra S, Kumar B, Bhansali A, Chakrabarty A. Epidemiology of onychomycosis in patients with diabetes mellitus in India. Int J Dermatol 2002;41(10):647-651.

[28] Rothman LB, Cabib E. Regulation of glycogen synthesis in the intact yeasts cell. Biochemistry. 1979;8(8):3332-3341.

[29] Sert M, ilkit M, Tetiker T, Kucukcan A, Kose N. Diabetes mellitus and foot dermatomycosis. Is it really related? Turk J Infect 2001;15:341-343.

[30] Pièrard GE, Franchimont CP. The nail under fungal siege in patients with type II diabetes mellitus. Mycoses. 2005;48(5):339-342.

[31] Saunte DML, Holgersen JB, Haedersdal M, Strauss G, Bitsch $\mathrm{M}$, Svendsen OL, Arendrup MC, Svejgaard EL. Prevalence of toe nail onychomycosis in diabetic patients. Acta Derm Venereol. 2006;86(5):425-428.

[32] Levy LA. Epidemiology of onychomycosis in special risk populations. J Am Podiatr. Med Assoc. 1997;87(12):546-550.

[33] Lavery LA, Armstrong DG, Wunderlich RP, Mohler MJ, Wendel CS, Lipsky BA. Risk factors for foot infections in individuals with diabetes. Diabetes Care. 2006;29(6):1288-1293.

[34] Moghissi ES, Korytkowski MT, DiNardo M, Einhorn D, Hellman R, Hirsch IB, Inzucchi SE, Ismail-Beigi F, Kirkman MS, Umpierrez GE. American Association of Clinical Endocrinologists and American Diabetes Association consensus statement on in patient glycemic control. Diabetes Care. 2009;32(6):11191131.

[35] Greene RA, Scher RK. Nail changes associated with diabetes mellitus. J Am Acad Dermatol 1987;16(5):1015-1021.

[36] Winston J, Miller J. Treatment of onychomycosis in diabetic patients. Clinical Diabetes 2006;24(4):160-166. 